\title{
THE EFFECT OF IMPULSIVITY ON SABOTAGE BEHAVIOR OF SALES EMPLOYEES: THE MEDIATING ROLE OF AFFECTIVE DISORDER AND ORGANIZATIONAL BASED SELF-ESTEEM
}

\author{
DOI: 10.17261/Pressacademia.2019.1061 \\ PAP- V.9-2019(8)-p.36-42
}

Pelin Kanten ${ }^{1}$, Benan Arda ${ }^{2}$

${ }^{1}$ Canakkale Onsekiz Mart University, Faculty of Political Sciences, Canakkale, Turkey pelinkanten@comu.edu.tr, ORCID: 0000-0002-6487-0203

${ }^{2}$ Canakkale Onsekiz Mart University, Faculty of Political Sciences, Canakkale, Turkey benanciplak@gmail.com, ORCID: 0000-0001-7530-5966

\section{To cite this document}

Kanten, P., Arda, B. (2019). The effect of impulsivity on sabotage behavior of sales employees: the mediating role of affective disorders and organizational based self-esteem. PressAcademia Procedia (PAP), V.9, p.36-42

Permemant link to this document: http://doi.org/10.17261/Pressacademia.2019.1061

Copyright: Published by PressAcademia and limited licenced re-use rights only.

\begin{abstract}
Purpose- This study aims to investigate the effects of impulsivity on sabotage behaviors of sales employees and the mediating roles of affective disorders and organizational based self-esteem.

Methodology- For the purpose of the research, the data which were collected from 198 sales employees from shopping stores by the survey method were analyzed by using partial least squares-structural equation modeling method. While conducting analysis, Smart PLS program was used by applying bootstrapping technique (5000 resample) to determine the significance levels of the proposed hypotheses and also Anderson and Gerbing (1988) two-step approach has been used.

Findings- The results revealed that impulsivity has a positive and significant effect on affective disorder levels of employees and also impulsivity has a positive and significant effect on sabotage behavior levels of employees. However, research results indicate that impulsivity has a negative and significant effect on organization based self-esteem levels of employees and organization based self-esteem has a negative and significant effect on sabotage behavior levels of employees. In addition, it is found out organization based self-esteem has partially mediating role in the relationship between impulsivity and sabotage behaviors.

Conclusion- The study demonstrate that personality traits are one of the significant predictors of the maladaptive behaviors and psychological health problems in the service industry. However, this study reveals that in order to eliminating negative attitudes in the workplaces, organizations need to consider dispositional characteristics of the employees.
\end{abstract}

Keywords: Impulsivity, sabotage behaviors, affective disorders, sales employees JEL Codes: M10, M20, M54

\section{INTRODUCTION}

In today's organizations, it is needed to employ qualified and superordinate employees who will perform well. More specifically, some skills and abilities required in sales companies in order to selling products and services to the customers effectively. These features indicate that for sales occupations it is needed to persuade customers, to communicate and listen efficiently and to have tendency behave in a helpful manner (Klang, 2012: 1-2). In addition to these skills and abilities, some other characteristics come into prominence like personality which has a vital role separate individuals from each other. Personality considered as an enduring disposition which comprise of distinctive characteristics such as feelings, thoughts, attitudes and behaviors that leads to individuals to be unique (Waheed et al., 2017: 140). Impulsivity examined as one of the personality trait which refers to the tendency act without thinking, like to be risk-taking and willingness to make quick decisions out of planning. However, impulsivity reflects as the biological bases of the personality which lead to recognize individual differences (Shahjehan et al., 2012: 2188). On the other hand, impulsivity considered as a crucial characteristic as it leads to maladaptive behaviors like aggression, violence, sabotage and also causes some health problems such as depression, personality and affective disorders (Kanten, 2018: 731). Therefore, it can be inferred that due to the sales employees' characteristics play a vital role on sales companies' success, personality traits and its consequences should be explored. Accordingly, this study aims to examine one of the unfavourable personality trait which is called as impulsivity and its negative consequences in sales companies. From scope of the consequences of impulsivity; sabotage behavior, affective disorders and organizational based self-esteem are investigated. However, there is no research in the existing literature yet examining the relationships among impulsivity, affective disorder, sabotage behavior and organizational based self-esteem together. Consequently, this study aims to determine some of the causes of impulsivity, so it attempts to add contribution to the literature. 


\section{THEORETICAL FRAMEWORK AND HYPOTHESES DEVELOPMENT}

As a personality trait, it seen various definitions has been tried to identify impulsivity which are conflicting with each other. For example, impulsivity characterized as quickly response, risk taking, non-planning and lack of impulse control (Zadravec et al., 2005: 40). In addition, one of the well accepted definition of impulsivity defined "as a tendency toward rapidness and have willingness unplanned actions in response to external and internal stimuli regardless of the negative consequences" (Garofalo et al., 2018: 187). Due to the unfavourable outcomes and hardness of controlling impulses, impulsivity recognized a crucial component of individual's everyday life such as decisionmaking process and neuropsychiatric circumstances (Kanten, 2018: 733). However, it is suggested that impulsivity related to the several forms of psychopathological symptoms and maladaptive behaviors such as deviance, anti-social and sabotage (Komarovskaya et al., 2007: 1499). Sabotage refers to the inefficacy in the organization operations based on the employees' misbehaviors in the workplace (Ling et al., 2014: 215). Sabatoge behaviors is defined as to "damage, disrupt and collapse the organizations actions deliberately for the personal goals". However, these behaviors lead to unfavourable image, delaying in production and services, damaging properties and breakdown relationships in the extent of the organization (Ambrose et al., 2002: 948). In scope of the sabotage behaviors, it is seen that employees have a tendency to make retaliatory actions, slowdown of services, playing pranks, and expressing aggression towards to the customers in the organizations (Le and Ok, 2014: 176). These behaviors should be eliminated or minimized because they may affect the organizational survival and efficiency in the long term. Due to sabotage behaviors importance on service industry, it is seen researchers concerned about the antecedents such as demographic factors, relationships between employees with their colleagues and supervisors and organizational conditions (Suet et al., 2012: 1). In addition, from the individual perspective, it is suggested that risk taking attitudes, career orientation and personality traits considered as the significant precursors of the sabotage behaviors (Harris and Ogbonna, 2002: 179). For example, Giacalone and Knouse (1990) asserted that machiavellian and hostility personality lead employees to exihibit sabotage behaviors. Thomson (2017) indicated a significant relationship between neuroticism and sabotage. However, Værøy et al (2016) and Piko and Pinczés (2014) emphasized that impulsivity trait highly correlated with aggressive behaviors which is considered as scope of the sabotage. Komarovskaya et al. (2007) and Maneiro et al. (2017) studies asserted that impulsivity trait has a significant impact on the individual's anti-social behaviors.

Besides, within the scope of the individual components; researchers Chi et al. (2015) and Chi and Grandley (2019) emphasized that positive or negative moods related with the sabotage behaviors. Le and Ok (2014) indicated that emotional dissonance as one of the major sources of the sabotage behaviors. On the other hand, from the organizational perspective, based on the perception of powerlessness, frustration, facilitation of work, boredom and injustice, it is expected that employees have a tendency to exhibit sabotage behaviors (Ambrose et al., 2002: 948). In other words, considering the employees perceive incivility, conflict and poor relationships in the organization, they may demonstrate sabotage behaviors in the service delivery process (Kanten et al., 2015: 515). Therefore, it is possible to express that due to the employees negative perception related to their organizations, their organization based self-esteem levels may decrease and may have more disposition to exhibit maladaptive behaviors such as aggression, deviance or sabotage. In this context, it can be inferred that in the individualistic perspective, some unfavourable personality traits, mood and affective disorders; and as part of organizational conditions, organizational based self-esteem may lead individuals to exhibit sabotage behaviors, so the following hypotheses are proposed:

$\mathrm{H}_{1}$ : Impulsivity influences sales employees' sabotage behavior levels positively.

$\mathrm{H}_{2}$ : Affective disorders influences sales employees' sabotage behavior levels positively.

$\mathrm{H}_{3}$ : Organizational based self-esteem influences sales employees' sabotage behavior levels negatively.

Organizational based self-esteem refers to the degree to which an individual perceive himself or herself to be capable, valuable and significant as a member of the organization. In literature, it is suggested that organizational based self-esteem has a crucial predictor of the individual's positive and negative behaviors in the working area (Abas, et al., 2015: 100). Due to it's importance on some job attitudes, performance and wellbeing, researchers indicated the determinative factors of organizational based self-esteem. Accordingly, it is seen several predictors of this concept under the personality and working conditions. As scope of the personality, general self-esteem, general self-efficacy and emotional stability have regarded some of the antecedents of the individual's organizational based self-esteem levels (Bowling et al., 2010: 603). In other words, since the individuals have positive characteristics, they will believe valued and respected in their organizations so it is expected that their organizational based self-esteem levels increase. On the other hand, in case of the individuals possess unfavourable traits such as hostility and impulsivity, it is anticipated that their organizational based self-esteem levels were affected negatively, so the following hypothesis is proposed.

$\mathrm{H}_{4}$ : Impulsivity influences employees' organizational based self-esteem levels negatively.

However, it is asserted that impulsivity considered as the antecedents of some psychiatric health problems such as attentiondeficit/hyperactivity, borderline personality, depression, obsessive-compulsive disorder, substance abuse and affective disorders (Stanford et al., 2009: 385). Affective disorders or mood disorders are characterized as penetrant dysregulation of affectives and psychmotor activities which is correlated with biological and cognitive components (Akıskal, 2004: 1). Affective disorders differiantated from the moods, affectives or emotions based on some characteristics. For example, affective disorders are usually more intense and take long time than normal mood (DBSA, 2017: 1). However, mood or affective disorders are lead to loss of quality of life and dsyfunctionality in the life of individual, so due to its mental and somatic effects which causes should be explored and eliminated (Jacobi et al., 2005: 3). In the literature, it is suggested that affective disorders are related with family history and some risk factors such as cognitive style, self-esteem, interpersonal relations and personality factors (Duffy, 2000: 340). Krueger et al., (2003); Klein et al., (2011) suggested that personality is one of the significant precursors of the affective disorders. Thus, it is possible to express that some unfavorable personality traits may lead to affective disorders, so the following hypothesis is proposed:

$\mathrm{H}_{5}$ : Impulsivity influences sales employees' affective disorder levels negatively. 
In addition, it is also supposed that one of the dispositional characteristic and organizational condition considered as a mediator variable. It is expected that affective disorders and organizational based self-esteem have a mediating effect between the relationship impulsivity and sabotage behaviors, as a result the following hypotheses are proposed:

$\mathrm{H}_{6}$ : Affective disorders has a mediating role on the relationship between impulsivity and sabotage behaviors.

$\mathrm{H}_{7}$ : Organization-based self-esteem has a mediating role on the relationship between impulsivity and sabotage behaviors.

Figure 1: Research Model

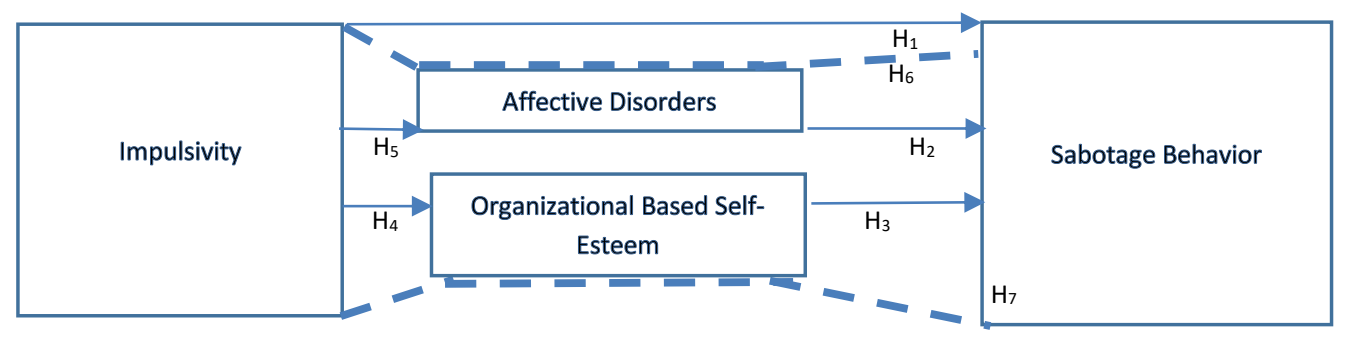

\section{RESEARCH METHODOLOGY}

\subsection{Sample and Procedures}

The present sample of the research was composed of two shopping center sales employees which are located in Çanakkale province. The participants constituted of 198 employees who have been working in these shopping center stores determined by a convenient sampling method. Out of 250 questionnaires that have been sent out, 205 have been returned, representing a response rate of $82 \%$. After the elimination of the cases that have incomplete data and outliers, 198 questionnaires (79\%) have been accepted as valid and included in the evaluations. However, questionnaire survey method is used for data collection in this study. The questionnaire form contains four different measures related to research variables. Out of the 198 respondents, 55\% were male and $45 \%$ were female; $39 \%$ were between 18 and 25 years, $37 \%$ were between 26 and 33 years, $24 \%$ were older than 34 years; $33 \%$ of the total respondents had a high school degree, $29 \%$ of them had a vocational school degree, whereas $38 \%$ had a bachelor's degree. From the working position perspective, most of (74\%) the employees were working as a sales representative and $26 \%$ of them working as a sales manager. In addition, majority of participants (74\%) had been working between 1 and 3 years, 18\% of them had been working between 4 and 7 years and $8 \%$ of them had been working more than 8 years in the retailing industry.

\subsection{Measures}

The measures used in the questionnaire forms have been adapted from the previous studies in the literature. Affective disorder scale have been adapted to Turkish, other scales were taken from the Turkish literature and a pilot study has been conducted for the validity of these measures. As a result of the pilot study, some corrections were made in the questionnaire forms. A Likert-type metric, that is, expressions with five intervals has been used for answers to the statements of survey. Anchored such; "1- strongly disagree, 2- disagree, 3- agree or not agree, 4- agree, 5-strongly agree". Moreover, 5 demographic questions were included in the questionnaire form. Firstly, all scales were subjected to the exploratory factor analyses to check the dimensions, and then confirmatory factor analyses were applied to all scales.

- Impulsivity Scale: Impulsivity scale was taken from Kanten (2018) study. Exploratory factor analyses using principle component analysis with varimax rotation was applied to the adapted scale to check the dimensions. As a result of the impulsivity scale variables, 6 items were removed from the analysis due to the factor loading under 0.50 and four factor solutions (negative urgency, sensation-seeking, lack of premeditation, and lack of perseverance) were obtained in accordance with the theoretical structure. Some examples of the items asked to the employees are as follows: "When I am upset I often act without thinking"; "I have trouble controlling my impulses".

- Sabotage Behavior Scale: Individuals' sabotage behavior levels were measured with 10 items which was developed by Harris and Ogbonna (2006). As a result of the exploratory factor analyses, 3 items were removed from the analysis due to the factor loading under 0.50 and one factor solution were obtained in accordance with the theoretical structure. Some examples of the items asked to the employees are as follows: "In this organizations, employees mess things up deliberately"; "In this organization, employees slow down service when they want to".

- Affective Disorder Scale: Individuals' affective disorder levels were measured with 10 items of "Emotional Regulation Questionnaire" which was developed by Gross and John (2003). As a result of the exploratory factor analyses, 3 items were removed from the analysis due to the factor loading under 0.50 and one factor solution were obtained in accordance with the theoretical structure. Some examples of the items asked to the employees are as follows: "When I am feeling negative emotions, I make sure not to express them; "When I'm faced with a stressful situation, I make myself think about it in a way that helps me stay calm".

- Organizational Based Self-Esteem Scale: Individuals' organizational based self-esteem scale levels were measured with 10 items which were taken from Fan (2008) study. As a result of the exploratory factor analysis of the data related to the organization-based self-esteem variables, 1 item removed from the analysis due to the factor loading under 0.50 and one factor solution obtained in accordance with the theoretical structure. Some examples of the items are as follows: "I am a valuable part of this place"; "I am trusted around here". 


\subsection{Data Analysis}

SPSS for Windows 22 and SmartPLS v3 were used to analyze the obtained data. SPSS 22 version used for the descriptive statistics and reliability analysis and assessing the demographic profile of the sample. Smart PLS v3 used for testing the hypotheses by employing partial least squares-structural equation modeling method. Therefore, partial least squares (PLS) based SEM was used in this study. PLS is considered as a well known method for estimating path coefficients in structural models and also it is seen prominent in management literature in the last decade due to its capable under the non-normality conditions and small samples (Ali and Kim, 2015: 302). While conducting analysis, Smart PLS program was used by applying bootstrapping technique (5000 resample) to determine the significance levels of the proposed hypotheses and also Anderson and Gerbing (1988) two-step approach has been used. According to this approach, first the measurement model needs to be tested by performing validity and reliability for the each measure. After obtaining acceptable values, it can be proceed with the structural model.

\section{RESEARCH FINDINGS}

\subsection{Measurement Model}

In scope of the measurement model, convergent validity and discriminant validity were tested. Within the convergent validity, factor loadings, composite reliability (CR), and average variance extracted values were computed. Table 1 shows that factor loadings exceeded the recommended value of 0.6 and composite reliability values greater than the recommended value of 0.7 and also average variance extracted is exceeded the recommended value of 0.5 (Hair et al., 2006).

Table 1: Summary Table of Validity and Reliability

\begin{tabular}{|l|l|c|c|c|}
\hline Variables & $\begin{array}{l}\text { Factor } \\
\text { Loadings }\end{array}$ & Cronbach's Alpha & $\begin{array}{c}\text { Composite Reliability } \\
\text { Average Variance } \\
\text { Extracted (AVE) }\end{array}$ \\
\hline Impulsivity & $0.664-0.734$ & 0.760 & 0.837 & 0.506 \\
\hline Affective Disorder & $0.766-0.856$ & 0.841 & 0.893 & 0.675 \\
\hline Organizational Based Self-Esteem & $0.686-0.819$ & 0.908 & 0.924 & 0.577 \\
\hline Sabotage Behavior & $0.661-0.833$ & 0.851 & 0.890 & 0.577 \\
\hline
\end{tabular}

The next step as part of the measurement model was to assess the discriminant validity. Discriminant validity provided when the square root of the AVE (diagonal values) of each construct is larger than its corresponding correlation coefficients (Fornell \& Larcker, 1981). Table 2 shows that each indicator's loadings on its own construct are higher than all cross loadings with other constructs. Thus, it can be said that measurement model showed convergent validity and discriminant validity criteria were provided.

Table 2: Discriminant Validity

\begin{tabular}{|l|c|c|c|c|}
\hline & $\begin{array}{c}\text { Affective } \\
\text { Disorder }\end{array}$ & Impulsivity & Sabotage Behavior & $\begin{array}{c}\text { Organizational Based Self- } \\
\text { Esteem }\end{array}$ \\
\hline Affective Disorder & $\mathbf{0 . 8 2 2}$ & & & \\
\hline Impulsivity & 0.516 & $\mathbf{0 . 7 1 2}$ & & \\
\hline Sabotage Behavior & 0.273 & 0.352 & $\mathbf{0 . 7 5 9}$ & \\
\hline Organizational Based Self-Esteem & -0.336 & -0.405 & -0.435 & $\mathbf{0 . 7 5 9}$ \\
\hline
\end{tabular}

\subsection{Structural Model}

With using Smart PLS v3 and bootstrapping procedure by 5000 iterations structural model and hypotheses were tested. In this step, for the explanation power the standardized $\mathrm{R}^{2}$ and for assessing the model fit standardised root mean square residual (SRMR) were computed. In this model SRMR value was observed 0.074 which is under the recommended value of 0.08 , shows that model has an acceptable. Standardized $R^{2}$ refers to the explonatory level of independent variable on dependent variable. Therefore, the independent variable (impulsivity) and the mediator variables (affective disorder and organizational based self-esteem) explain $22 \%$ of the employees sabotage behaviors. In addition, impulsivity explains both $26 \%$ of the affective disorder level of employees and $16 \%$ of their organizational based selfesteem levels. Figure 2 shows the results of the structural model analysis 


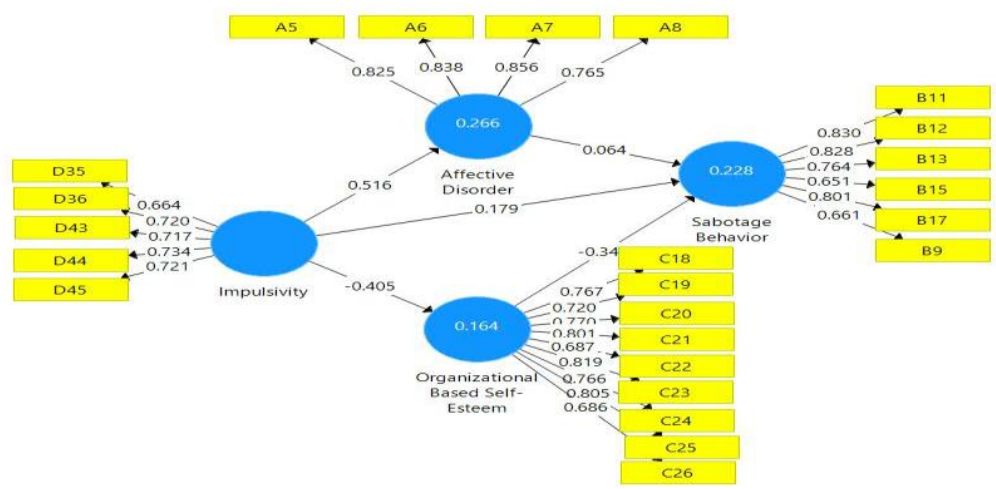

After giving structural model, the direct and indirect effects of structural model and hypotheses testing are presented in Table 3.

Table 3: Direct and Indirect Effects of Structural Model and Path Coefficients

\begin{tabular}{|c|c|c|c|c|}
\hline Hypotheses & $\boldsymbol{\beta}$ & T values & P Values & Results \\
\hline$\longrightarrow$ Sabotage Behavior & 0.179 & 2.048 & 0.041 & Supported \\
\hline $\mathrm{H}_{2}$ : Affective Disorder $\longrightarrow$ Sabotage Behavior & 0.064 & 0.710 & 0.478 & Not Supported \\
\hline $\mathrm{H}_{3}$ : Organization Based Self Esteem $\longrightarrow$ Sabotage Behavior & -0.341 & 4.260 & 0.000 & Supported \\
\hline $\mathrm{H}_{4}:$ Impulsivity $\longrightarrow$ Organization Based Self-Esteem & -0.405 & 6.304 & 0.000 & Supported \\
\hline $\mathrm{H}_{5}:$ Impulsivity $\longrightarrow$ Affective Disorder & 0.516 & 10.243 & 0.000 & Supported \\
\hline $\mathrm{H}_{6}:$ Impulsivity $\rightarrow$ Affective Disorder $\rightarrow$ Sabotage Behavior & 0.033 & 0.686 & 0.493 & Not Sup \\
\hline $\mathrm{H}_{7}:$ Impulsivity $\rightarrow$ Org.Based Self-Esteem $\rightarrow$ Sabotage Behavic & 0.138 & 3.650 & 0.000 & Supported \\
\hline
\end{tabular}

According to table 3 , it is possible to express that the path parameter and significance levels show that impulsivity has a positive and significant effect on affective disorder level of employees $(\beta=0.516$; $t$-value $=10.243)$ and also impulsivity has a positive and significant effect on sabotage behavior level of employees ( $\beta=0.179$; $t$-value $=2.048$ ), so $\mathrm{H}_{5}$ and $\mathrm{H}_{1}$ hypotheses were supported. However, research results indicate that impulsivity has a negative and significant effect on organization based self-esteem level of employees $(\beta=-0.405 ; t-v a l u e=6.304)$ and $\mathrm{H}_{4}$ hypothesis was supported. In addition, it is seen that organization based self-esteem ( $\beta=-0.341 ; \mathrm{t}$-value $=4.260$ ) has a negative and significant effect on sabotage behavior levels of employees so $\mathrm{H}_{3}$ hypothesis was supported. Besides, affective disorder has no significant effect on employees' sabotage behavior levels and $\mathrm{H}_{2}$ hypothesis was not supported. In this study, it is tested the mediating effect of affective disorder and organizational based self-esteem on the relationship between impulsivity and sabotage behavior. As to examine the mediating effects, Preacher and Hayes (2008), a bootstrap procedure was used to test the indirect effects of impulsivity on sabotage behavior via affective disorders and organizational based self-esteem. For model 1 , the regression coefficients of the mediator effect of affective disorders in the relationships between impulsivity and sabotage behaviors $(\beta=0.033 \mathrm{p}>0.05)$ and the bootstrap confidence interval [-.054; .138] contain zero, thus it does not corresponds to the criterion of significance of the mediator effect of affective disorders between impulsivity and sabotage behavior, so $\mathrm{H}_{6}$ hypothesis was not supported. For model 2 , the regression coefficients of the mediator effect of organization based self-esteem in the relationships between impulsivity and sabotage behaviors $(\beta=0.138 p<0.001)$, and the bootstrap confidence interval [.065; 212] does not contain zero. Thus it corresponds to the criterion of significance of the mediator effect of organization based self-esteem between impulsivity and sabotage behavior, so $\mathrm{H}_{7}$ hypothesis was supported. In order to estimate the size of the indirect effects of mediators, VAF \% (Variance Accounted For) was calculated. For model 2, the VAF value is $26.8 \%$ indicating that $26.8 \%$ of the total effect of impulsivity on sabotage behavior is explained by indirect effect (organizational based self-esteem), so it is possible to express that, there is partially mediating effect.

\section{CONCLUSION}

Impulsivity considered as an undesirable personality construct in social and work life due to it leads to unplanned and spontenous attitudes. It is suggested that impulsivity traits cause to some maladaptive behaviors such as anti-social, deviance, sabotage and also bring about critical health problems like personality disorders, substance use disorders, attention deficit and affective disorders. Specifially, based on the intense customer-employee interaction, personality traits have precedence over in the sales organizations, as to eliminating unfavourable attitudes. In other words, it is needed to employ favourable employees and make an effort to gain organizational survival by reducing deviance and sabotage behaviors. Sabotage behaviors are considered as negative attitudes which are directed to the customers and have significant effect on service delivery process adversely. These behaviors demonstrated by the employees due to their dispositional characteristics, their emotions or moods and organizational conditions. Therefore, it can be inferred that sabotage behaviors based on the personality traits, affective states and employees perceptions of their organizations. Accordingly, in scope of this study, both some individual and organizational 
antecedents of sabotage behaviors were evaluated. That is to say, from the individual perspective impulsivity trait and affective disorders and in terms of organizational precursors organizational based self-esteem were examined.

As a result of the research findings, it has been revealed that impulsivity traits has a positive and significant effect on sales employees' sabotage behaviors. This result shows that employees who have some characteristics such as risk taking, unplanning and non-thinking may easily exhibit retalitary actions, aggresive attitudes and slowdown service process towards to the customers. In addition, it is found that impulsivity lead to sales employees to have some affective disorders. Because impulsivity represent a personality traits which include have no controlling impulse so it is expected that these individual's lability of mood. Besides, it is found that impulsivity has a significant and negative effect on sales employees' organization based self-esteem levels. According to this result, it can be inferred that due to the impulsive individuals possess negative emotions and insights, they may believed that their organization not valued and respected to themselves. Moreover, it is seen that organization based self-esteem effects sales employees sabotage behaviors negatively. Thus, incase of the employees have a proud as belonging to member of the organization and perceived that they are significant and competent, it is expected that these employees abstain from exhibiting sabotage behaviors. Besides, it was found that, organizational based self-esteem had a partially mediator role on the relationship between impulsivity and sabotage behaviors. It can be inferred that, while sales employees have impulsivity traits, it is expected that their sabotage behaviors may decrease incase of they have organizational based self-esteem. That is, impulsive employees may demonstrate some negative behaviors towards to customers, but if they believed that they are valuable and important, have a tendency to behave in a more positive manner.

Consequently, it is possible to express that sabotage behaviors based on the individual and organizational conditions. In the literature, there are some studies related to the individual and organizational antecedents of the sabotage behaviors, but there is no study which focus on impulsivity, affective disorders, organizational based self-esteem and sabotage behaviors together in the retailing or service industry. Due to these industries characteristic, employees need to have favoruable traits, positive emotions and moods and required to exhibit positive behaviors. However, based on the results, it can be supposed to hire and employ individuals who have positive features which faciliate to decrease of the adverse attitudes of employees in the service organizations. In addition, it is needed to determine individuals whether some psyhological disorders or not. Incase of the employees have affective or psyshological disorders, they may have directed for treatment so it can be diminished negative behaviors noticeably. On the other hand, incase of the organization consider their employees valuable and important, it is expected they have withdrawal to behave negatively. For future studies, it is recommended that the research model can be tested different samples of service sectors such as health, tourism and transportation wihch shows the sabotage behavior greater importance. Moreover, from the individualistic perspective personality disorders, dark traits, self-efficiacy and positive psychological capital can be investigated. As a mediator organizational attachment or job embeddedness may be taken.

\section{REFERENCES}

Abas, C., Omar, F., Halim, F. W., \& Hafidz, S. W. M. (2015). The mediating role of organizational-based self-esteem in perceived organizational support and counterproductive work behaviour relationship. International Journal of Business and Management, 10(9), 99-108. doi:10.5539/ijbm.v10n9p99.

Akıskal, H. S. (2004). Mood disorders: clinical features. Kaplan \& Sadock's Comprehensive Textbook of Psychiatry, 1-55.

Ali, F. \& Kim, W.G. (2012). Creative Tourists' Experience: Does it Predict Satisfaction, Nostalgia Intensity and Behavioural Intentions. International Interdisciplinary Business-Economics Advancement Conference, Conference Proceedings, November 16-21, 2015, Ft. Lauderdale, Florida, USA, ISSN: 2372-5885, 296-307.

Ambrose, M.L., Seabright, M.A. ve Schminke, M. (2002). Sabotage in the workplace: The role of organizational injustice, Organizational Behavior and Human Decision Processes 89, 947-965.

Anderson, J.C. \& Gerbing D.W. (1988). Structural equation modelling in practice: A review and recommended two-step approach. Psychological Bulletin, 3 (3), 411-423.

Bowling, N.A., Eschleman, K.J., Wang, Q., Kirkendall, C. \& Alarcon, G. (2010). A meta-analysis of the predictors and consequences of organization-based self-esteem. Journal of Occupational and Organizational Psychology, 83, 601-626.

Chi, N. W., \& Grandey, A. A. (2019). Emotional labor predicts service performance depending on activation and inhibition regulatory fit. Journal of Management, 45(2), 673-700.

Chi, N. W., Chang, H. T., \& Huang, H. L. (2015). Can personality traits and daily positive mood buffer the harmful effects of daily negative mood on task performance and service sabotage? A self-control perspective. Organizational Behavior and Human Decision Processes, 131, $1-15$.

DBSA (2017). Understanding your mood an introduction to depression and bipolar disorder. Depression and Bipolar Support Alliance, 1-22.

Duffy, A. (2000). Toward Effective Early Intervention and Prevention Strategies for Major Affective Disorders: A Review of Antecedents and Risk Factors. Can J Psychiatry, 45, 340-348.

Fan, T. L. (2008). The mediating role of organizational-based self-esteem in training-commitment relationship. Hong Kong Baptist University.

Fornell, C., \& Larcker, D. F. (1981). Evaluating structural equation models with unobservable variables and measurement error. Journal of Marketing Research, 18(1), 39-50.

Garofalo, C., Velotti, P., Callea, A., Popolo, R., Salvatore, G., Cavallo, F. \& Dimaggio, G. (2018). Emotion Dysregulation, Impulsivity and Personality Disorder Traits: A Community Sample Study, Psychiatry Research, 266, 186-192. 
Giacalone, R. A., \& Knouse, S. B. (1990). Justifying wrongful employee behavior: the role of personality in organizational sabotage. Journal of Business Ethics, 9, 55-61.

Gross, J.J., \& John, O.P. (2003). Individual differences in two emotion regulation processes: Implications for affect, relationships, and wellbeing. Journal of Personality and Social Psychology, 85, 348-362.

Hair, J. F., Black, W. C., Babin, B. J., Anderson, R. E., \& Tatham, R. L. (2006). Multivariate Data Analysis (6th ed.), Upper Saddle River, NJ: Prentice-Hall.

Harris, L. C., \& Ogbonna, E. (2002). Exploring service sabotage: the antecedents, types and consequences of frontline, deviant, antiservice behaviors. Journal of Service Research, 4(3), 163-183.

Harris, L.C. \& Ogbonna, E. (2006). Service Sabotage: A Study of Antecedensts and Consequences, Journal of the Academy of Marketing Science, 34(4), 543-558.

Jacobi, F., Rosi, S., Faravelli, C., Goodwin, R., Bouchez, S. A., \& Leapine, J. P. (2005). The epidemiology of mood disorders. Mood Disorders: Clinical Management and Research Issues, 1-34.

Kanten, P., Kanten, S., Yeşiltaş, M. \& Yaşlıoğlu, M. (2015). Ücret Adaletinin Hizmet Süreçlerini Sabote Etme ve Sosyal Kaytarma Davranışları Üzerindeki Etkisinde Ücret Eşitliği Algısının Rolü. 23. Ulusal Yönetim Ve Organizasyon Kongresi Bildiriler Kitabı, 14-16 Mayıs 2015, Muğla, 513520.

Kanten, P. (2018). The individual antecedents of impulsive behavior. İşletme Araştırmaları Dergisi, 10(3), 732-746.

Klang, A. (2012). The relationship between personality and job performance in sales: a replication of past research and an extension to a Swedish context. Dynamic Work Solitions.

Klein, D.N., Kotov, R., Bufferd, S.J. (2011). Personality and Depression: Explanatory Models and Review of the Evidence. Annu Rev Clin Psychol. 2011; 7: 269-295.

Komarovskaya, I., Loper, A. B., \& Warren, J. (2007). The role of impulsivity in antisocial and violent behavior and personality disorders among incarcerated women. Crımınal Justıce and Behavıor, 34(11), 1499-1515.

Krueger, R. F., \& Tackett, J. L. (2003). Personality and psychopathology: working toward the bigger picture. Journal of Personality Disorders, $17(2), 109-128$

Lee, J H., \& Ok, C. M. (2014). Understanding hotel employees' service sabotage: Emotional laborperspective based on conservation of resources theory, International Journal of Hospitality Management, 36, 176-187.

Ling , I-L., Marshall , R. Xu, Y. \& Lin,W.Y. (2014). Jaypatient-Induced Service Sabotage Behavior: The Issue of Self-Esteem of Hospital Nurses, Health Marketing Quarterly, 31(3), 213-230.

Maneiro, L., Gomez-Fraguela, J.A., Curtin, O. \& Romero, E. (2017). Impulsivity traits as correlates of antisocial behavior in adolescents. Personality and Individual Differences, 104, 417-422.

Piko, B. F., \& Pinczés, T. (2014). Impulsivity, depression and aggression among adolescents. Personality and Individual Differences, 69, 3337.

Preacher, K. J., \& Hayes, A. F. (2008). Asymptotic and resampling strategies for assessing and comparing indirect effects in multiple mediator models. Behavior Research Methods, 40, 879-891. doi:10.3758/BRM.40.3.879.

Shahjehan, A., Qureshi, J. A., Zeb, F., \& Saifullah, K. (2012). The effect of personality on impulsive and compulsive buying behaviors. African Journal of Business Management, 6(6), 2187-2194.

Stanford, M.S., Mathias, C.W., Dougherty, D.M., Lake, S.L., Anderson, N.E. \& Patton, J.H. (2009). Fifty years of the Barratt Impulsiveness Scale: An Update and Review, Personality and Individual Differences, 47, 385-395.

Suet, C.W., Huiey, L.P., Lin, L.S. \& Ling, L.W. (2012). Service Sabotage in the Service Industry in Malaysia. Degree of Bachelor of International Business (Hons) Universiti Tunku Abdul Rahman.

Thomson, W. (2017). Sabotaging the self-a trait? and it's relationship with neuroticism. Clinical and Experimental Psychology, 3(4), 1-4. doi:10.4172/2471-2701.1000175

Værøy, H., Western, E., \& Andersson, S. (2016). The link between facets of impulsivity and aggression in extremely violent prisoners. Open Journal of Psychiatry, 6, 86-94

Waheed, A., Yang, J., \& Webber, J. (2017). The effect of personality traits on sales performance: an empirical investigation to test the fivefactor model (ffm) in Pakistan. Interdisciplinary Journal of Information, Knowledge and Management, 12, $139-157$.

Zadravec, T., Bucik, V., \& Socan, G. (2005). The place of dysfunctional impulsivity in the personality structure. Horizons of Psychology, 14(2), 39-50. 